\title{
Desafios de familiares no cuidado domiciliar da criança em uso de cânula de traqueostomia
}

\author{
Home care challenges facing families of children using a tracheostomy cannula \\ Desafíos de familiares en el cuidado domiciliario al niño en uso de cánula de traqueotomía
}

\author{
Priscila Machado de Araújo Bossa'; Sandra Teixeira de Araújo Pacheco"; Bárbara Bertolossi Marta de Araújo"I, \\ Michelle Darezzo Rodrigues Nunes ${ }^{\prime V}$, Liliane Faria da Silvav ${ }^{v}$, Juliana Maria Rêgo Maciel Cardoso ${ }^{\text {II }}$
}

\begin{abstract}
RESUMO
Objetivo: descrever os desafios enfrentados por familiares para cuidar da criança com traqueostomia no domicílio. Método: pesquisa descritiva, qualitativa, desenvolvida através da análise de conteúdo, pela perspectiva do referencial teórico de Collière. Foram entrevistados oito familiares de crianças com traqueostomia, na faixa etária entre 3 e 9 anos acompanhadas em um ambulatório pediátrico no município do Rio de Janeiro, no período de janeiro a maio de 2016. Resultados: os desafios envolveram principalmente o enfrentamento da nova realidade, as novas demandas de cuidado, a dificuldade com a aquisição de materiais e a limitação no convívio social da criança. Para superar as dificuldades os familiares cuidadores reinventam as estratégias de cuidado a fim de preservar a vida. Conclusão: foram identificadas condutas que oferecem risco à saúde dessas crianças, apontando a necessidade de instrumentalizar as práticas dos familiares para a manutenção adequada e segura das vias aéreas no ambiente domiciliar.
\end{abstract}

Descritores: Enfermagem pediátrica; criança; traqueostomia; família.

\begin{abstract}
Objective: to describe the challenges faced by family members in providing home care for children with tracheostomy. Method: this qualitative, descriptive study, applied content analysis from the perspective of Collière's theoretical framework. Eight family members of children with tracheostomies, aged between 3 and 9 years, treated at a pediatric outpatient clinic in Rio de Janeiro city, were interviewed between January and May 2016. Results: the main challenges found were coping with the new situation, new care demands, difficulty acquiring material, and limitations on social life. To overcome the difficulties, family caregivers reinvent care strategies in order to preserve lives. Conclusion: behaviors that pose risks to these children's health were identified, pointing to the need to equip families' care practices so that they can maintain airways properly and safely at home. Descriptors: Pediatric nursing; child; tracheostomy, family.
\end{abstract}

\section{RESUMEN}

Objetivo: describir los desafíos enfrentados por familiares para cuidar al niño con traqueotomía, en el domicilio. Método: investigación descriptiva, cualitativa, desarrollada a través del análisis de contenido, desde la perspectiva del marco teórico de Collière. Se entrevistaron ocho familiares de niños con traqueotomía, con edad entre 3 y 9 años, cuyo seguimiento tuvo lugar en un ambulatorio pediátrico situado en el municipio de Río de Janeiro, de enero a mayo de 2016. Resultados: los desafíos involucraron principalmente el enfrentamiento de la nueva realidad, las nuevas demandas de cuidado, la dificultad en la adquisición de materiales y la limitación en la convivencia social del niño. Para superar las dificultades, los familiares cuidadores reinventan las estrategias de cuidado con fines de preservar la vida. Conclusión: se identificaron conductas que representan riesgos a la salud de estos niños, lo que señala la necesidad de instrumentalizar las prácticas de los familiares para el mantenimiento adecuado y seguro de las vías respiratorias en el entorno del hogar.

Descriptores: Enfermería pediátrica; infantil; traqueotomía; familia.

\section{INTRODUÇÃO}

A sofisticação tecnológica e o desenvolvimento dos recursos medicamentosos e terapêuticos resultaram em um novo grupo de crianças sobreviventes dos agravos perinatais, doenças crônicas e traumas, as quais são denominadas como Children with Special Health Care Needs por sua fragilidade e dependência de cuidados para sobreviver ${ }^{1}$.

'Enfermeira. Mestre. Universidade do Estado do Rio de Janeiro. Brasil. E-mail: prisciladearaujo@gmail.com

"Enfermeira. Doutora. Professora Adjunta, Universidade Estado do Rio de Janeiro. Brasil. E-mail: stapacheco@yahoo.com.br

I'Enfermeira. Doutora. Professora Adjunta, Universidade Estado do Rio de Janeiro. Brasil. E-mail: betabertolossi@gmail.com

IVEnfermeira. Doutora. Professora Adjunta, Universidade Estado do Rio de Janeiro. Brasil. E-mail: mid13@hotmail.com

vEnfermeira. Doutora. Professora Adjunta, Universidade Federal Fluminense. Brasil. E-mail: lili.05@hotmail.com

V'Enfermeira. Mestre. Professora Assistente, Universidade Federal do Rio de Janeiro. Brasil. E-mail: julianahfse@gmail.com

VIIAgradecimentos à Coordenação de Aperfeiçoamento de Pessoal de Nível Superior - CAPES. 
No Brasil, essa população foi denominada de Crianças com Necessidades Especiais de Saúde (CRIANES). Geralmente, esse grupo requer acompanhamento de reabilitação a longo prazo, e cuidados diferenciados da equipe de enfermagem, em todos os níveis de atenção em saúde, devido à necessidade de cuidados múltiplos, complexos e contínuos $^{2}$.

Essas crianças apresentam demandas de cuidado classificadas em seis tipos. O primeiro, de desenvolvimento, inclui crianças com atraso de desenvolvimento. No segundo, de cuidados tecnológicos, estão as crianças que utilizam dispositivos mantenedores da vida. No terceiro, estão as que fazem uso contínuo de fármacos. No quarto, referente aos hábitos modificados, as crianças precisam de adaptações nas atividades rotineiras. No quinto, relativo aos cuidados mistos, as crianças possuem uma ou mais demandas anteriores, excluindo-se a tecnológica. $E$, o sexto resume as demandas de cuidados clinicamente complexos, possuem todas as anteriores inclusive o manejo de tecnologias para suporte de vida ${ }^{3,4}$. Entre os grupos de crianças com necessidades especiais de saúde, destacam-se neste estudo aquelas com demanda de cuidado tecnológico - em uso de cânula traqueal.

A criança que utiliza este dispositivo apresenta uma inerente fragilidade oriunda da exposição das vias aéreas inferiores através do estoma e a presença constante da cânula, e quando no domicílio exige vigilância continuada e, principalmente, cuidados específicos por parte dos familiares cuidadores a fim de preservar sua vida e propiciar seu bem-estar ${ }^{5}$.Esses familiares por vezes não possuem conhecimento adequado a realização de tais cuidados, o que pode implicar complicações no quadro clínico da criança e seu consequente retorno ao hospital ${ }^{4}$.

O dispositivo tecnológico é um elemento de proteção que evita hospitalização não eletiva, entretanto requer a implementação de ações educativas, relacionadas ao manuseio e cuidados específicos de cada dispositivo ${ }^{6}$. Contudo, é necessário conhecer os desafios confrontados pelos cuidadores, diariamente. Assim, o estudo objetivou descrever os desafios enfrentados pelos familiares para cuidar da criança em uso de cânula de traqueostomia no domicílio.

\section{REFERENCIAL TEÓRICO}

O alicerce teórico deste estudo pautou-se nas contribuições de Collière sobre o cuidado. Em sua teoria identificaram-se dois tipos de cuidados de natureza diferente, denominados de cuidados de manutenção da vida, e cuidados de reparação. O primeiro trata de ações cotidianas e habituais relacionadas com a manutenção e continuidade da vida, que contribuem para o desenvolvimento do ser humano, como comer, evacuar e se locomover; ou de natureza psicoafetiva. Já os cuidados de reparação propiciam a continuidade da vida, buscando limitar a doença, lutar contra ela, combater suas causas e tratá-la7.

Quando ocorre o predomínio dos cuidados de reparação sobre os cuidados cotidianos e habituais ocorre uma anulação gradual das forças vivas da pessoa, resultando na exaustão física, mental ou social ${ }^{7}$.

A criança em uso de cânula de traqueostomia no domicílio está inserida no contexto de modificações significativas para ela e para sua família, com demandas de cuidado que não pertencem ao saber comum.

\section{METOdologia}

Estudo descritivo com abordagem qualitativa. Participaram oito familiares cujos critérios de inclusão foram: ser familiar cuidador de crianças em uso de cânula de traqueostomia, com idade entre 3 e 9 anos de idade, atendidas em um ambulatório pediátrico, localizado no município do Rio de Janeiro.

Dos nove familiares cuidadores atendidos nesse ambulatório e que correspondiam aos critérios de inclusão, oito aceitaram participar. Foram excluídos os familiares cuidadores de crianças em uso de cânula de traqueostomia que estavam hospitalizadas e os familiares cuidadores menores de 18 anos.

Neste estudo, familiar cuidador é compreendido como a pessoa que assume a responsabilidade pelo cuidado de alguém doente ou dependente devido a um vínculo parental, não necessariamente por uma ligação consanguínea ${ }^{8}$.

Como estratégia para a captação dos participantes, foi realizado contato telefônico, a partir dos dados da criança registrados pela instituição. Esse primeiro contato propiciou identificação do familiar cuidador e oportunizou o convite para um encontro agendado, conforme a sua conveniência.

Os dados foram coletados no período de janeiro de 2016, a maio de 2016 por meio de entrevistas semiestruturadas, com a seguinte questão orientadora: Você encontra alguma dificuldade para cuidar de sua criança com traqueostomia? Fale-me sobre isso.

Todas as entrevistas foram feitas pela primeira autora em local reservado, com média de duração de 30 minutos. As falas foram gravadas e transcritas na íntegra. Para garantir o anonimato dos participantes, eles foram identificados pela letra $E$, seguida de um algarismo arábico, conforme a ordem das entrevistas. Para o encerramento das entrevistas,

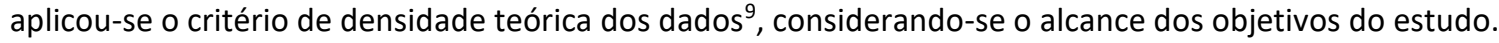


A análise do material empírico ocorreu em três fases, seguindo o proposto na modalidade temática ${ }^{10}$ : pré-análise; exploração do material e a categorização dos dados, que resultou em quatro categorias analíticas: Adaptação ao dispositivo traqueal; Modificações no manejo de cuidados da criança com cânula de traqueostomia; Aquisição de materiais para o cuidado domiciliar da criança; A cânula de traqueostomia limitando o convívio social da criança.

O projeto de pesquisa foi aprovado pelo Comitê de Ética em Pesquisa da referida instituição, sob número 1.349.663. Ademais, todos os participantes assinaram o Termo de Consentimento Livre Esclarecido.

\section{RESULTADOS E DISCUSSÃO}

Entre os oito participantes do estudo, a maioria dos entrevistados pertence ao grupo materno, na faixa etária de 40 anos, com baixa escolaridade e renda familiar de até dois salários mínimos. Quanto às crianças, quatro são préescolares menores de 6 anos de idade, e quatro escolares com idades entre 6 e 9 anos. Quanto ao tempo de uso da cânula, variou de 8 meses até 9 anos.

O tratamento dos dados resultou em quatro categorias analíticas que são discutidas a seguir.

\section{Categoria 1: Adaptação ao dispositivo traqueal}

O impacto da descoberta da necessidade do uso da cânula traqueal na criança foi um dos desafios evidentes nos depoimentos dos familiares cuidadores, resultando em sentimentos de choque e medo.

No começo foi muito difícil. Porque foi tudo novo para mim [...] foi um choque mesmo! Eu enfrentei isso [...] porque ela precisava fazer a cirurgia e usar a cânula. [...] o médico me falou que a vida dela dependia disso. (E3)

Ao constatar a presença de um problema de saúde de um filho, os familiares cuidadores manifestam a ansiedade em relação ao futuro, medo, conflitos internos, impotência e, ainda, a adaptação à nova realidade ${ }^{11}$.

Além disso, a realização da traqueostomia implica mudanças no cotidiano da família diante da dependência da criança ao dispositivo traqueal e das demandas de cuidados por ele gerados.

[...] no hospital tenho a segurança de que se acontecer qualquer coisa [...] as enfermeiras vêm nos socorrer, mas na nossa casa? Chegamos uma vez em casa, ele estava com a respiração carregada. Corri para o hospital! Quando cheguei no hospital me explicaram que eu precisava aspirar a cânula [...] isso aconteceu no primeiro dia, após a alta hospitalar. (E8)

Cuidar de uma criança dependente de tecnologia requer treinamento e orientações dos profissionais de saúde, considerando que no domicílio esta responsabilidade será do familiar cuidador, que prestará cuidados que até então eram realizados por uma equipe especializada no âmbito hospitalar ${ }^{12}$.

Para Collière, o cuidado, para garantir a manutenção e a continuidade da vida, não é simples. O processo de cuidar envolve manter a vida assegurando a satisfação de um conjunto de necessidades essenciais à sobrevivência ${ }^{13}$

Nessa perspectiva, a atuação do enfermeiro é primordial, orientando e dando voz ao familiar cuidador. É preciso incentivá-lo a enfrentar o momento, esclarecendo suas dúvidas e anseios para promover a qualidade de vida criança com cânula de traqueostomia?.

\section{Categoria 2: Modificações no manejo de cuidados da criança com cânula de traqueostomia}

Esta categoria trata das dificuldades encontrados pelos familiares cuidadores para realizar a rotina de cuidados que foi intensamente modificada pela presença da cânula traqueal.

Nos cuidados relacionados ao banho da criança com dispositivo traqueal, um familiar cuidador revelou:

Foi muito difícil. Porque era na banheira pequena [...] e com muita dificuldade eu conseguia dar o banho nele [...] porque ele tem muita dificuldade para ficar sentado[...] e ele não fica em pé [...]. Mas logo demos nosso jeito! [...] meu marido cortou um latão ao meio, e fez uma banheira enorme para o nosso garoto. Ele pintou [...] ficou a coisa mais linda do mundo! (E1)

Além das demandas de cuidados referentes ao uso da cânula traqueal, algumas dessas crianças precisam enfrentar, ainda, as dificuldades advindas da condição física limitante em função do comprometimento neurológico. Assim, conforme o último relato, para propiciar o banho com mais conforto para seu filho, o pai da criança confeccionou uma banheira com os recursos presentes em casa, oferecendo cuidado na perspectiva que Collière aponta como de confortação ${ }^{14}$.

[...] foi muito difícil, porque eu tinha medo de molhar, de entrar água pela cânula, de sufocar e não perceber, sabe? Foi muito difícil [...] por isso eu colocava pouca água, ai eu dava o banho nela, bem devagar [...] com cuidado. (E3) 
A possibilidade de entrar água na cânula de traqueostomia e não notar, e em decorrência disso causar danos à criança também se mostrou uma preocupação da família. Para atenuar esse problema, sua estratégia foi de colocar menos água na banheira e conjuntamente prestar o banho devagar, revelando-se o cuidado de preservação da vida ${ }^{14}$, buscando afastar riscos à saúde da criança.

Considerando que o banho é uma prática relativa ao bem-estar da criança, o enfermeiro precisa dispensar um olhar atento a fim de, em conjunto com o familiar cuidador, desenvolver novas práticas com o propósito de oferecer segurança e qualidade de vida a essa criança e ao seu familiar.

A preocupação com a água do banho faz parte do aprendizado da rotina de cuidados da criança em uso da cânula de traqueostomia. Esse medo de molhar tem origem nas recomendações fornecidas no treinamento, em que reforçam a precaução para de não deixar a criança ficar muito tempo dentro da água e de não molhar a fixação da cânula ${ }^{3}$.

Os familiares apontaram estratégias utilizadas diante das secreções na cânula de traqueostomia:

É muita, muita secreção mesmo! Eu só aspiro [...] às vezes, eu tenho que fazer a nebulização, para poder soltar [fluidificar a secreção]. [...] ela faz a fisioterapia respiratória para poder ajudar [...]. Às vezes, eu fico doida! (E7)

O uso de medicamentos, da nebulização e os exercícios respiratórios na tentativa de diminuir o acúmulo de secreção na cânula de traqueostomia da criança são apontados como estratégias específicas do cuidar, nessa condição.

Essas ações são recomendadas para a prevenção da obstrução da cânula, e são indicadas a todas as crianças traqueostomizadas, devendo ser enfatizadas pela equipe de enfermagem. Essas medidas incluem: aspiração regular com técnica correta, pelo menos três vezes ao dia e quando houver evidência de secreção em vias aéreas; umidificação da secreção; fisioterapia respiratória para melhor mobilização das secreções ${ }^{15}$.

Mencionaram-se também as lesões causadas pela cânula de traqueostomia na região adjacente ao estoma traqueal.

[...] eu coloco a gaze para não machucar embaixo da [cânula] da traqueostomia, porque, às vezes, machuca muito [...], porque ele tosse demais [a cânula move-se ferindo a pele ao redor do estoma], aí ele se machuca muito. (E1)

No que diz respeito à presença contínua de umidade na pele, estudo aponta a possibilidade de desenvolver um eritema, por isso indica-se a frequente troca dos curativos para manter a pele seca e evitar a maceração de tecidos e a ruptura na pele ${ }^{16}$.

As mães destacam também a preocupação com a facilidade da entrada de corpos estranhos, como insetos e detritos suspensos no ar na cânula traqueal.

[...] quando a gente vai ao ar livre, eu tenho medo de bicho [...] a gente sempre tem que olhar. Às vezes acontece de a gente caminhar e vir aquele vento de poeira, de lixo [...] aí, coloco-o ao contrário da direção do vento, para não pegar nele [para não entrar corpo estranho na cânula]. (E4)

Neste sentido, o cuidado de inspecionar com frequência a cânula de traqueostomia, quando se está ao ar livre, e de posicionar a criança do lado oposto ao vento foram estratégias citadas.

Estudo prévio aconselha evitar contato com poeira, fumaça, pêlo de animais, pós, cremes gordurosos, pomadas e sprays, pois podem causar irritação pulmonar. Além disso, indica manter longe das crianças objetos pequenos ou brinquedos que possam ser introduzidos na cânula de traqueostomia, afastando também causas comuns de obstruções em crianças $^{17}$.

Nas falas evidenciaram-se os desafios dos familiares cuidadores frente à descanulação traqueal de suas crianças, denotando situações emergenciais:

[...] uns 15 dias após a alta hospitalar, a cânula [traqueal] dela soltou, de madrugada; quando eu acordei, eu vi o último suspiro dela, [estava] toda geladinha, quase sem respiração! E eu procurando a cânula pela cama dela. [...] Quando achei, peguei rapidinho! Fiz a higienização rápida, e coloquei de volta. Aí corri, liguei o aspirador, meu marido me ajudou a aspirar ela. [...] depois que eu aspirei a respiração dela foi voltando [...]. (E2)

Diante desse relato, essa família vivenciou situação de potencial risco de vida, em razão da descanulação acidental de sua criança.

A questão da descanulação também emergiu entre os participantes de outra pesquisa que demonstraram dúvidas e preocupações em relação às emergências que podem ocorrer com a exteriorização dos dispositivos tecnológicos ${ }^{4}$. $A$ descanulação acidental requer a substituição imediata da cânula. Embora algumas crianças tenham a traqueia rígida fazendo com que a via aérea permaneça parcialmente aberta quando o tubo é removido, outras crianças possuem a cartilagem traqueal com malformação ou flexível, resultando em colapso da via aérea quando a cânula é removida ${ }^{18}$. 
Nesse contexto, observa-se que o familiar cuidador não somente realiza as práticas de cuidado da criança com cânula de traqueostomia, mas busca estratégias para conservar a sua vida ${ }^{14}$.

\section{Categoria 3: Aquisição dos materiais para o cuidado domiciliar da criança}

Foi possível observar nas falas dos familiares os desafios para adquirir os materiais necessários ao cuidado da criança com cânula de traqueostomia.

[..] uma dificuldade é a falta de material, essas sondas [de aspiração] utilizamos muitas vezes! Mas a gente dá nosso jeito para aspirar [...] [recentemente] tinha acabado as sondas, e onde eu moro não tem [para comprar], é muito complicado para achar. Conheci um rapaz que vende, mas ele quer me vender 100 sondas! Eu não tenho condição de comprar 100 sondas. (E8)

Nota-se a dificuldade de o familiar cuidador encontrar a sonda de aspiração na cidade onde reside, e quando encontra só consegue adquiri-la em grande quantidade, e desse modo não tem condições financeiras para a compra, desvelando uma questão desafiadora para essa família.

O impacto financeiro dessas famílias é significativo, pois na maioria das vezes as mães deixam de trabalhar fora e realizar atividades remuneradas, e o recurso financeiro fica apenas sob a responsabilidade do pai da criança. Vale destacar que o custo da família é mais alto, tendo em vista a necessidade de suprimentos tecnológicos para a manutenção da vida da criança ${ }^{19}$.

Outro familiar, diante da necessidade da aquisição de materiais para o cuidado de sua criança, revela que tenta buscar doações dos materiais no ambulatório, onde sua filha recebe atendimento.

Eu peguei umas [sondas de aspiração] no ambulatório, e ganhei algumas [de conhecidos], e às vezes compro também [...]. Ainda vou entrar com pedido na defensoria pública para tentar conseguir [os materiais]. [...] Para você conseguir as coisas é uma burocracia danada [...] tinha que ser mais fácil! (E7)

A dificuldade de obter os materiais básicos para os cuidados dessas crianças gera angústia nos familiares cuidadores. Desse modo, eles procuram estratégias que possibilitem a aquisição dos materiais necessários e vão construindo uma rede de apoio com os serviços de saúde que costumam frequentar, e ainda estão dispostos lutar por meios judiciais a fim de adquirir os recursos indispensáveis.

Nesse contexto, forma-se uma rede informal de ajuda que pode incluir instituições religiosas, organizações não governamentais (ONGs) e pessoas conhecidas que se disponibilizam oferecer ajuda. As famílias buscam recursos alternativos lançando mão de apelos para doações de materiais que viabilizem o cuidado com sua CRIANES ${ }^{19}$.

Assim, evidencia-se que apesar de existirem dispositivos legais que garantam os direitos das CRIANES no Brasil, na prática, muitas vezes, os familiares vivem uma verdadeira peregrinação para garanti-los. Por vezes, necessitando de determinações judiciais para assegurar o tratamento adequado aos seus filhos ${ }^{20}$.

Devido à dificuldade de obter os materiais para as práticas de cuidado com suas crianças, os familiares revelaram a estratégia de reutilização de materiais, como a sonda de aspiração e o cadarço fixador.

[...] a gente não tem aquele sustento para comprar esses materiais, [por isso] tem que lavar para utilizar novamente [...] sempre reuso o amarrador. [...] reutilizo a sonda também, porque senão é muito gasto. $E$ o hospital não dá. poderia dar aquele conjunto de materiais, todos os meses, para cuidar dele, mas a gente não tem, então vamos reutilizando [...] (E4)

A aspiração da cânula traqueal é um cuidado frequente na rotina dessas famílias, a este respeito, conforme estudo, as sondas de aspiração podem ser usadas mais de uma vez antes de serem descartadas no lixo, se o paciente necessitar de aspirações frequentes. Para tanto, deve-se lavar a sonda em água corrente e limpa, e mantê-la limpa guardada na embalagem original ou em um recipiente de uso exclusivo ${ }^{21}$.

\section{Categoria 4: A cânula de traqueostomia limitando o convívio social da criança}

Os familiares apontaram os desafios referentes ao convívio social da criança que tem o dispositivo traqueal. A possibilidade de a criança expelir secreção pela cânula de traqueostomia em outras pessoas, primeiramente, em ambientes públicos gera ansiedade, medo e constrangimento por parte dos familiares.

[...] deveria ter um protetor para essa [cânula de] traqueostomia [...] para não ficar mostrando. [...] às vezes, quando a gente conversa com as pessoas, ele espirra em cima de você, em cima dos outros. Acho que um protetor [para a cânula traqueal] serviria para evitar passar por esse constrangimento [...]. (E4)

Ainda sobre a preocupação social, refere-se também ao sentimento de vergonha diante de tal situação.

Ele espirra secreção demais nos outros, [...] onde minha cara vai parar? Aí não dá. Que vergonha! [...]. E é embaraçoso, porque ele joga muita secreção [para] muito longe, [...]. A gente que é mãe, pai suporta tudo, mas o pessoal de fora não, vai ter um pouco de nojo! Assim, não vão querer ficar perto dele e eu não vou gostar disso. 
Observou-se que algumas famílias optam por minimizar as saídas do domicílio devido ao constrangimento que podem ocorrer em ambientes extradomiciliares.

[...] é muito difícil passear [...]. Quase não saio mais com ele. Porque eu fico com medo de acontecer alguma coisa por causa dessa [cânula de] traqueostomia. Só dentro de casa. (E5)

A cânula de traqueostomia tornou-se o fator decisivo para a mãe desejar manter o filho somente no espaço social de sua casa, apontando ser o domicílio o local onde se sente mais segura para atender às demandas que julga necessárias à preservação da vida de sua criança.

Ainda, há o receio do enfrentamento social por causa da estética da criança, que recebe influência da cultura e dos padrões sociais. Destaca-se que as sequelas estéticas geram influências significativas sobre o comportamento de outrs pessoas, como reações de estranheza e rejeição, causando sentimento de vergonha e/ou constrangimento por parte dos clientes ${ }^{22}$.

\section{CONCLUSÃO}

O estudo permitiu conhecer as práticas de cuidados, os desafios vivenciados e as estratégias criadas pelos familiares para a manutenção da vida dacriança que utiliza a cânula de traqueostomia no domicílio.

A adaptação ao dispositivo traqueal exige mudanças no cotidiano familiar devido à dependência da criança e as novas demandas de cuidados. Ainda, envolve uma série de sentimentos, como o sofrimento para aceitar a nova realidade, a insegurança diante dos novos cuidados para a manutenção da vida, além da sensação de impotência e o medo do futuro.

As modificações no manejo de cuidados dessa criança estão relacionadas à aquisição de saberes interdisciplinares e à adequação de cuidados cotidianos, que se tornaram complexos e frequentes, a fim de suprir as necessidades imprescindíveis à sua sobrevivência.

A aquisição de materiais para o cuidado domiciliar da criança é complexa, visto que a maioria das famílias não tem condições para compra-los; se não conseguem doações, reutilizam os materiais.

A cânula de traqueostomia limita o convívio social, pois a possibilidade de a criança expelir secreção, a insegurança de realizar os cuidados fora do domicílio e, ainda, o enfrentamento social devido à alteração corporal geram receio das manifestações de estigmas, preconceitos, que acabam por isolar a criança e seu cuidador.

Este estudo desvelou as reinvenções das formas de cuidar, assim como destacou as vulnerabilidades das práticas de cuidados desenvolvidas pelos familiares da criança portadora de cânula de traqueostomia, revelando a necessidade de melhor instrumentalizá-los.

É preciso desenvolver programas específicos para o acompanhamento e suporte dos familiares e de suas crianças, possibilitando meios para que elas tenham assistência de melhor qualidade, bem como os seus direitos da infância e cidadania respeitados.

\section{REFERÊNCIAS}

1. Arrué AM, Neves ET, Magnago TSBS, Cabral IE, Gama SGN, Hökerberg YHM. Translation and adaptation of the Children with Special Health Care Needs Screener to Brazilian Portuguese. Cad. Saúde Pública (Online). 2016 [cited 2018 Apr 8]; 32(6):e00130215. DOI: http://dx.doi.org/10.1590/0102-311X00130215

2. Cabral IE, Moraes JRMM. Family caregivers articulating the social network of a child with special health care needs. Rev. bras. enferm. (Online). 2015 [cited 2018 Apr 7]; 68(6):769-76. DOI: http://dx.doi.org/10.1590/0034-7167.2015680612i

3. Góes FGB, Cabral IE. Discourses on discharge care for children with special healthcare needs. Rev. bras. enferm. (Online). 2017 [cited 2018 May 15]; 70(1):154-61. DOI: http://dx.doi.org/10.1590/0034-7167-2016-0248

4. Viana IS, Silva LF, Cursino EG, Conceição DS, Góes FGB, Moraes JRMM. Educational encounter of nursing and the relatives of children with special health care needs. Texto \& contexto enferm. [internet]. 2018 [cited 2018 May 23]; 27(3):e5720016. DOI: http://dx.doi.org/10.1590/0104-070720180005720016

5. Schweiger C, Manica D, Becker CF, Abreu LSP, Manzini M, Sekine L, et al. Tracheostomy in children: a ten-year experience from a tertiary center in southern Brazil. Braz. J. Otorhinolaryngol. [internet]. 2017 [cited 2018 Apr 8]; 83(6): 627-32. DOI: http://dx.doi.org/10.1016/j.bjorl.2016.08.002

6. Okido ACC, Pina JC, Lima RAG. Factors associated with involuntary hospital admissions in technology-dependent children. Rev. Esc. Enferm. USP. [internet]. 2016 [cited 2018 Jun 2]; 50(1):29-35. DOI: http://dx.doi.org/10.1590/S0080-623420160000100004

7. Collière MF. Promover a vida: da prática das mulheres de virtude aos cuidados de enfermagem. Lisboa (Pt): Lidel; 1999.

8. Bicalho CS, Lacerda MR, Catafesta F. Reflection on whom the family caregiver is. Cogitare enferm. [internet]. 2008 [cited 2018 May 12]; 13(1):118-23. Available from: https://revistas.ufpr.br/cogitare/article/view/11972/8443

9. Fontanella BJB, Ricas J, Turato ER. Saturation sampling in qualitative health research: theoretical contributions. Cad. Saúde Pública (Online). 2008 [cited 2018 May 13]; 24(1):17-27. Available from: http://www.scielo.br/pdf/csp/v24n1/02.pdf 
10. Bardin L. Análise de conteúdo. São Paulo: Edições 70; 2011.

11. Simonasse MF, Moraes JRMM. Children with special health care needs: impact on familiar daily routine. J. res. fundam. care (Online). 2015 [cited 2018 May 13]; 7(3):2902-9. DOI: http://dx.doi.org/10.9789/2175-5361.2015.v7i3.2902-2909

12. Lima MF, Arruda GO, Vicente JB, Marcon SS, Higarashi IH. Technology dependent child: unveiling the reality of the family caregiver. Rev. Rene. [internet]. 2013 [cited 2018 May 29]; 14(4):665-73. Available from: http://periodicos.ufc.br/rene/article/view/3516/2758

13. Morais FRC, Silva CMC, Ribeiro MCM, Pinto NRS, dos Santos I. Restoring nursing as the practice of maintaining life: Collière Planning. Rev. enferm. UERJ. [internet]. 2011 [cited 2018 May 16]; 19(2):305-10. Available from: http://www.facenf.uerj.br/v19n2/v19n2a22.pdf

14. Collière MF. Cuidar... a primeira arte da vida. $2^{\text {a }}$ ed. Loures (Pt): Lusociência; 2003.

15. Piccinin IFDM, Bittencourt PFS, Bié IMG, Tavares LAF, Mesquita TCL, Lopes AM, Nascimento NG. A multidisciplinary teambased model of assistance for children with tracheostomy. Rev. Med. Minas Gerais. [internet]. 2016 [cited 2018 Apr 6]; 26 (Supl 6): S19-S26. DOI: http://dx.doi.org/10.5935/2238-3182.20160053

16. Morris LL, Whitmer A, McIntosh E. Tracheostomy care and complications in the intensive care unit. Crit. Care Nurse. [internet]. 2013 [cited 2018 Apr 6]; 33(5):18-30. DOI: http://dx.doi.org/10.4037/ccn2013518

17. Avelino MAG, Maunsell R, Valeraf FCP, Netog JFL, Schweiger C, Miura CS, et al. First Clinical Consensus and National Recommendations on Tracheostomized Children of the Brazilian Academy of Pediatric Otorhinolarygology (ABOPe) and Brazilian Society of Pediatrics (SBP). Braz. J. Otorhinolaryngol. [internet]. 2017 [cited 2018 May 16]; 83(5): 498-506. DOI: https://doi.org/10.1016/j.bjorl.2017.06.002

18. Hockenberry MJ, Wilson D. Wong Fundamentos de enfermagem pediátrica. 9ạ ed. Rio de Janeiro: Elsevier; 2014.

19. Simonasse MF, Moraes JRMM, Góes FGB, Silva LF, Magalhães LS, Pacheco STA. Families' economics difficulties on caring for children with special health care needs. Enfermería Comunitaria [internet]. 2018 [cited 2018 Aug 03]; 14. Available from: http://ciberindex.com/c/ec/e11136

20. Góes FGB, Cabral IE. Hospital discharge in children with special health care needs and its different dimensions. Rev. enferm. UERJ. [internet]. 2017 [cited 2018 Apr 28]; 25:e18684. DOI: https://doi.org/10.12957/reuerj.2017.18684

21. Ministério da Saúde (Br). Hospital Alemão Oswaldo Cruz. Orientações para o cuidado com o paciente no ambiente domiciliar. Brasília (DF): Ministério da Saúde; 2018.

22. Reis AT, Santos RS. The feelings of women-mothers faced with the surgery in newborn birth defects. Esc. Anna Nery. Rev. Enferm. [internet]. 2011 [cited 2018 May 20];15(3):490-96. DOI: http://dx.doi.org/10.1590/S1414-81452011000300007 